$$
\text { "tmcs-ambrus" — 2012/11/18 — 12:51 — page } 231 \text { — \#1 }
$$

\title{
The application of modelling tasks in the classroom - why and how? With reflections on an EU teacher training course
}

\author{
Gabriella Ambrus, ÖDÖn Vancsó and Balázs Koren
}

Abstract. The aim of the article is to present the concept of mathematical modelling in the classroom. LEMA (Learning and Education in and through Modelling and Applications) was an EU Comenius funded project in which mathematics educators from six countries worked to produce materials to support teachers' professional development. A group of voluntary Hungarian mathematics teachers were taught modelling for a year and we were and still are given feedback continously. The article leads us from the general concept of mathematical modelling to its practice in the classroom. It presents difficulties that teachers have to face when doing modelling lessons and their students' reactions are also mentioned. We present sample tasks from the material of the teacher training course as well as tasks that were created by the participants.

Key words and phrases: modelling, teaching, modelling tasks, problem solving.

ZDM Subject Classification: M10, U10, U30.

\section{Introduction}

The question of teaching applications has earned a fairly important place in recent decades' studies of didactics of mathematics. Several different approaches have come out within individual subjects and with considering the interrelation of subjects, too. It is worth mentioning that there are different teaching methods associated with the teaching of applications, eg.: the application-centered, the realistic teaching of mathematics and the project method - and for Hungarian 


$$
\text { "tmcs-ambrus" — 2012/11/18 — 12:51 — page } 232 \text { — \#2 }
$$

examples: the competency-based teaching, where the emphasis is laid differently, though the main goal is obtaining knowledge with the capacity of using applications. The definition of mathematical literacy for PISA is:

"Mathematical literacy is an individual's capacity to identify, and understand, the role that mathematics plays in the world, to make well-founded judgments and to use and engage with mathematics in ways that meet the needs of that individual's life as a constructive, concerned, and reflective citizen."

Encouraging the growth of this talent is quite an interesting goal in case of mathematics, where due to the nature of the subject, correspondence to the real world does not become obvious for many - not even by the end of their studies. The theory that those having obtained firm mathematical foundations will easily be able to apply their knowledge in practice has not generally been proven. PISA results, among others, refer to this (2000, 2003, 2006, 2009).

According to the pedagogical and psychological examination into the so-called "insufficient application" of knowledge, the knowledge that has been acquired in schools where most typically the cognitive areas are developed, remain quite typically within the premises of the school, and can hardly be transferred to everyday use. [13]. Thus the application, the capacity of practical usage, cannot be expected to be formed upon the basis of traditional education. The obvious solution in order to reach our goals would be to introduce and use applications in the classroom on a daily basis. One possibility is the application of the gained knowledge outside mathematics, which has already appeared in mathematics teaching for quite a time with more or less emphasis and with more or less real practical relations (word-problems, real life based tasks). The other opportunity is that the relation to reality appears in the process of mathematics teaching and is constantly present, in other words, "pure" mathematics and applications are not separated during teaching.

This approach has deep roots within mathematics education, since mathematics and its applications were not separated until the $20^{\text {th }}$ century. [2]

Perhaps the most important example for this non-separation in the course of history is Archimedes, who quite frequently used methods and/or instruments of physics or other fields of life for proving his mathematical presuppositions. [11]

This latter opportunity is one of the main conceptions of the realistic mathematics teaching which was initiated by Freudenthal, which focuses on the methodological opportunities in the field of applying modelling tasks in the mathematics lesson among today's greatly altered boundaries. These boundaries mean the 
present science of mathematics on the one hand and social, economical requirements and claims on the other.

In the followings we are to examine how can the application of modelling tasks be built in the learning of mathematics, and then we give an account of a teacher training course on modelling.

\section{Applying modelling tasks and learning mathematics}

\subsection{Basics}

Modelling: abstraction of reality by mathematical procedures. [6]

This definition may lead us to a deeper analysis of modelling tasks and their solution, the modelling process. Criteria for modelling tasks.

Open, complex, realistic, authentic, problem providing, possible to solve using the modelling cycle [9] There are several different diagrams showing the modelling cycle. [1]. These are all cyclic and they connect the real world and mathematics.

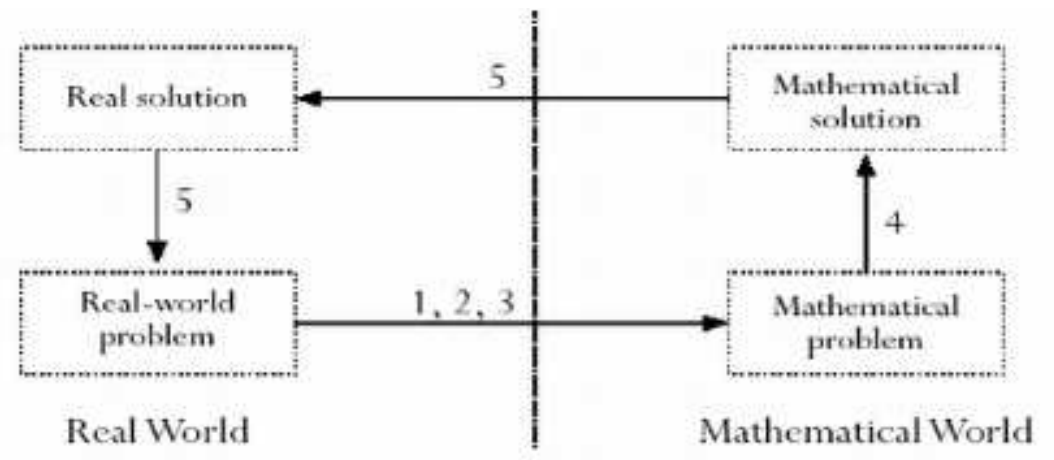

Figure 1. PISA 2003

As a simple diagram we present the one already shown in the 2003 PISA experiment (Figure 1) and another more detailed one (Figure 2). 


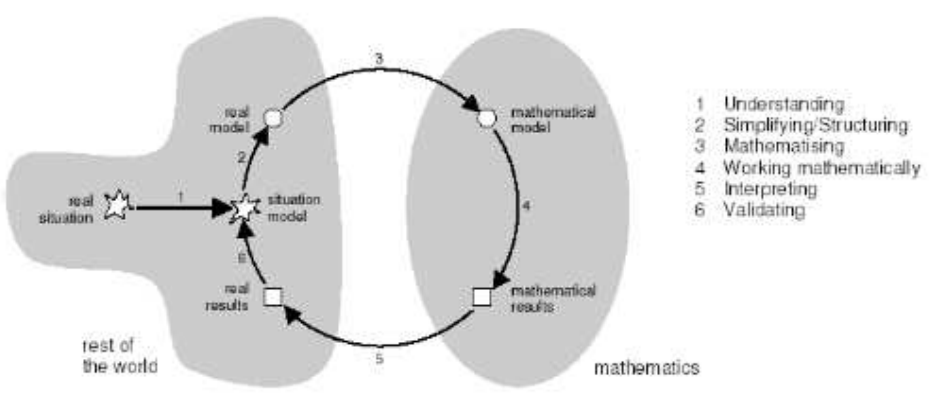

Figure 2. Blum and Leiß (2007)

The LEMA ${ }^{1}$ website presents sample modelling tasks in order to examine the steps of the modelling process.

The problem solving and modelling procedures bear quite a few resemblances to each other. Greefrath [6] speaks about strong structural likeness and on the basis of Figure 1. according to Pólya's steps of problem solving.

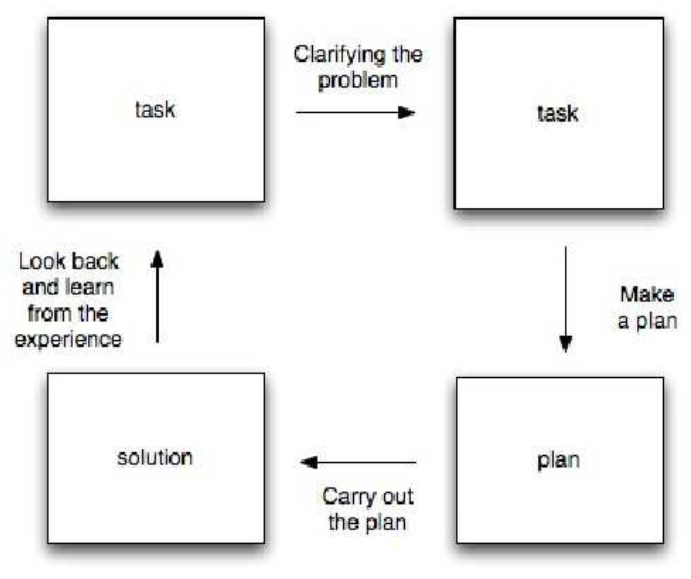

Figure 3. Pólya's steps

According to Pólya's steps [12] we can create another chart, which is more relevant to the second one.

${ }^{1} \mathrm{http}: / /$ www.lema-project.org 


$$
\text { "tmcs-ambrus" — 2012/11/18 - 12:51 — page 235 — \#5 }
$$

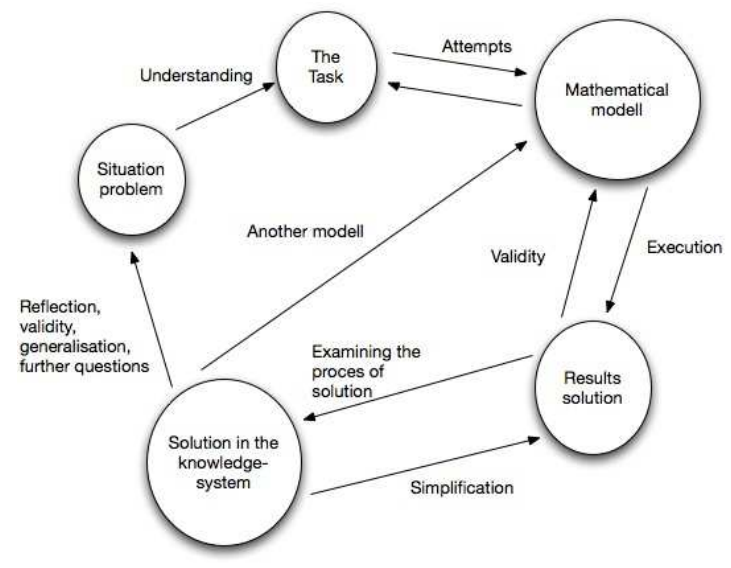

Figure 4

The above presented diagrams show that both procedures are cyclic. Each modelling cycle can be made up of smaller cycles. As one can see, both situations are problem solving ones, their difference is whether they are aiming for a mathematical solution or one outside mathematics. Upon the above information, we can establish that modelling usually helps learning problem solving procedures.

\subsection{Applying mathematical knowledge and modelling}

When preparing either a mathematical model or a mathematical solution, the student are selecting from their previous knowledge, and looking for the possible connections or relationships they might make use of. They apply these in a partly known way, though there might also be need for new, unusual applications, too. This leads to the re-arrangement of the previous knowledge and the opening of new contents which facilitate deeper understanding.

Likewise, previous methods might also be expanded, and furthermore: "Attempts to use a known procedure in an unfamiliar context can lead to generation of a new or modified procedure, which may or may not have conventional mathematical validity." [15]

Thus non-conventional methods might end up in experiences that lead us towards new knowledge and contents. The latter procedures are fairly important from the point of giving the appropriate account of mathematics. If the ready knowledge and models are the only ones to be used during applications, it can 


$$
\text { "tmcs-ambrus" — 2012/11/18 — 12:51 — page 236 — \#6 }
$$

easily lead to the misconception that mathematics is nothing but a storehouse for this kind of knowledge, and only those things on stock can be used - by choosing the right item of course - to solve the problems of reality. [4]

\subsection{Gaining new knowledge and modelling}

Certain questions and issues might emerge during the single steps, which will be quite difficult or impossible to solve with only the help of previous knowledge. Students might try to solve the problem taking a roundabout way. They can, for example, use a graphic calculator to find zero-points of certain functions, because they have never learnt solving higher-degree equations, or in order to define extremal values they apply graphic or other methods of continual approaches. The accuracy of these methods might be sufficient in certain situations. These experiences, however, are quite important from the learning aspect of the problem-solving process, too.

Such a situation might also be a good basis for students to understand that they lack further mathematical knowledge, in other words, the learning of mathematics is a never-ending process, which also means constant acquisition and broadening the knowledge.

With careful lesson-planning, the teacher might introduce new knowledge using an appropriate situation. Considering the complexity of the modelling tasks, this is not an easy objective for the teacher. In such a situation though, the teacher can always refer to the knowledge students lack, also mentioning when the curriculum presumably covers them (or not), connecting the previous, already existing knowledge to knowledge that is still to be (or might be) acquired.

For example, when talking about spherical geometrical knowledge and correlations, teaching spherical geometry first, and then asking questions such as "How can a Budapest-New York flight's shortest route be calculated, considering economic efficiency factors, too?" is not the sole possible choice. (In case of such a task though, several factors can interfere. The real route might not follow the calculated one, since the over-crowded air-space requires carefully planned airbridges in order to avoid crashes. These air-bridges might not allow the shortest possible route for the aircrafts to fly. Another issue might be the weather, since the shortest route might be quite dangerous because cyclonic storms for example. If that is the case, another route should be chosen. The first approach, however, should be the calculation of the shortest route, i.e. the length of a semi-circumference.) Dealing with the problem can also be turned upside down, when students have never heard anything about spherical geometry before, and 


$$
\text { "tmcs-ambrus" — 2012/11/18 — 12:51 — page } 237 \text { — \#7 }
$$

this lack of knowledge provides the motivation for the absorption in the topic. [8] Plenty of such examples can be given. These provide a kind of external motivation for the development of mathematics. This does not preclude the development of mathematical theories and instruments through internal mathematical problems. In the followings, motivation is going to be dealt with.

\subsection{Classroom motivation and modelling}

In the process of learning mathematics - similarly to learning basically anything - motivation has a key role. Usually there are only a few students who are honestly interested in real mathematical problems and enjoy dealing with them. Obviously, several methods should be tried out in order to raise interest, among which some are internal and others are external. Lacking appropriate motivation, learning mathematics is only a nuisance for many, which is soon to be forgotten after completing their studies. This fact makes it less probable for students to apply their mathematical knowledge outside the classroom, in real world situations.

Modelling tasks usually motivate students to deal with mathematics. A phenomenon has been observed, namely that in case of reality based situations which students are especially interested in (eg. fast-food restaurants, mobile phones) they not only enjoy solving the very task, but happily get absorbed in solving further "pure" mathematical tasks, and their enthusiasm might last for lessons waiting for the appearance of new, interesting topics. According to Zbiek, Conner (2006) three different kinds of motivation are supported by the modelling activity.

In case of the $1^{\text {st }}$ type, students' interest is aroused while learning about the situation, the problem itself and they perceive the connection between mathematics and the real world. They experience the fact, that mathematics might as well be useful in the world.

The $2^{\text {nd }}$ type provides motivation for learning mathematics or making progress in learning mathematics. During the mathematicising it gets more and more stressed, that mathematics itself can be the means of understanding the complexity of the world, whereas interpreting the results might justify that mathematics can really be useful in real-world situations.

The $3^{\text {rd }}$ type motivates for learning new knowledge and procedures. When, in the process of modelling, previous knowledge proves to be insufficient, it might urge on students the necessity of gaining new knowledge, or re-arrange the previous and try to use it in new context. See previous paragraph as well.

A $4^{\text {th }}$ type however can be added to the list, since for modelling not only mathematical knowledge is necessary, but for example knowledge in other sciences 


$$
\text { "tmcs-ambrus" — 2012/11/18 — 12:51 — page } 238 \text { - \#8 }
$$

is also needed. Experiencing in this might motivate learning other subjects as well as school work in general.

Solving modelling tasks provide students with unusual situations, where, for example, their time-honoured methods will not work, and they have to face the fact that logical reasoning and given circumstances can lead to a number of fairly different - correct solutions to a problem. Negative reactions to all these, or rather negative motivation might also occur - which a teacher should be prepared for, especially in the early phases of introducing modelling. It should be noted, though, that with the help of modelling tasks, the aim is to teach modelling itself, and it is not necessary for the teacher to make efforts to please all students similarly - as it is not required in any other subjects or topics either. [9]

\subsection{Communication and the modelling process}

The modelling process provides opportunity for its participants to learn and improve communication in connection with mathematics and in general as well. Understanding, grasping the problem, putting it into words, co-operating with others are all platforms where the communication ability can be developed. This also requires the knowledge and application of the technical jargon on the appropriate level.

In the course of co-operation students have to be able to formulate their ideas, understand others' conceptions, modify their own ideas in the mirror of these if necessary, and argue for their opinion. At the end of the modelling process students sum up, organise, present and discuss their results. In other words, there is active communication between teacher and student during the the raising and understanding of the problem, then between student and student if they work in groups. Then separate groups communicate with each other as they present their results in some way to each other. Finally, the evaluation is communication between the teacher and the groups. Several different kinds of communication occur while a modelling task is processed.

Generally it is an important challenge, and it has recently earned quite a significance that students should be able to communicate about mathematics, and later on be able to formulate their problems in the language of mathematics, so that an expert might be able to help them solve them. The social division of labour has reached such a height. [5]

Information technology today provides countless opportunities for solving advanced mathematical problems. A year ago wolframalpha.com was launched, with the help of which modelling tasks including advanced mathematical problems, like 
"tmcs-ambrus" — 2012/11/18 — 12:51 — page 239 — \#9

differential equations, integration, can easily be solved with only a few clicks. In case there is no expert available, this engine might prove an excellent means of computing for competent ones. While using wolframalpha.com the precise formulation of questions and providing relevant parameters are of essential importance. With the demonstration of results, the program offers sufficient help for students for the preparation of their presentations.

\subsection{Hungarian educational traditions and modelling}

This topic was already elaborated in our talk in a conference in Hamburg. This time we will only mention a few events from the past forty years.

Applying practical tasks was overshadowed in Hungarian mathematics education in the late 20th century. This fact can easily be illustrated by the tasks of the final examinations (Érettségi vizsga) of the period. While in 1963 all three tasks of the exam could be taken for modelling tasks, from 1973 there was usually none of the kind. From upper primary until the final examinations "pure, structuralist mathematics" became emphatic, which was supplemented by a high-level teaching of problem-solving skills.

The variety and standard of our numerous competitions in mathematics and our results in the international field are all stand to prove this. The best example is yet "KöMaL" a monthly journal in the topics of mathematics, physics and information technology, which aims at solving set problems at secondary level. Those who send their solutions in take part in a competition where they collect points. One hardly finds modelling tasks among the set problems. There are a few in information technology, but basically none in mathematics. See www.komal.hu

No sooner than in the past ten-fifteen years did the importance of solving practical tasks, the question of school knowledge and real-life applicability, and rooting from these, competency-based education gain ground. Modelling tasks can be quite successfully applied in such a mathematics education, where practical usage is considered essential and different competencies are widely developed.

According to experience, little is known about these by teachers and they are usually not used in classroom circumstances. There has of course been a slight improvement. It is worth having a look at mathematics teaching materials in Sulinova database, or the DQME-II EU project. Three Hungarian schools take part in this project which was launched in 11 countries with research scientists and school teachers. [10] 


$$
\text { "tmcs-ambrus" — 2012/11/18 — 12:51 — page } 240 \text { — \#10 }
$$

\section{Experiences of a teacher training course focusing on the application of modelling tasks}

The LEMA project ${ }^{2}$ was started in 2006 and ended in 2009. Its aim was to develop the subject matter of a teacher training course, which helps integrating mathematical modelling into the teaching practice of teachers at all levels (from primary to the final examinations) from all EU countries. The material of the course was competency-centered and preferred team work above all, so facilitated the spreading of several modern teaching methods.

In the followings, we are to present a few tasks from the Hungarian pilotcourse and in a brief analysis we will give account of the effects of it.

\subsection{Tasks prepared by the Hungarian participants}

As an important part of the course, the participants were asked to prepare modelling tasks during the module called "Tasks". The following compilation is a sample from these.

\subsubsection{Tasks for given situations}

A: Tasks developed from individual ideas

In the picture there is a several thousand year-old pyramid. What is the name of the building? Prepare its maquette. How much stone was needed for its construction? How long did it take to build it?
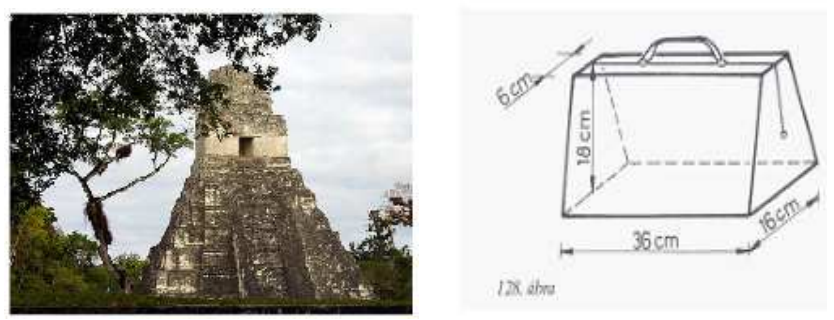

Figure 5. (a) Pyramid and (b) Bag

${ }^{2}$ for further information visit www.lema-project.org, a 6-language website or www.lemaproject.hu, which is under constant development and according to our hopes, it soon will be a meeting-point for those Hungarian teachers, who are interested in the topic. 


$$
\text { "tmcs-ambrus" — 2012/11/18 — 12:51 — page } 241 \text { — \#11 }
$$

B: Tasks developed on the basis of course-book tasks

Original tasks (from Matematika 12[7])

Calculate the volume of a bag which' lateral faces are 4 rectangles and 2 trapeziums. (see Figure 5: (b) Bag)

The original task can be transformed to a modelling task:

Mary is coming Hungary for a visit. Her bag is pictured in the illustration. She would like to buy some Boci and Tibi chocolate bars.

How many bars can she fit into her bag? Can she check her bag in without exceeding the weight limit? Is she going to be fined for smuggling?

\subsection{What effect did the course have on the participants?}

To get a more factual picture on the effects of the course, we carried out some further examinations using available documents, as follows:

(1) Knowledge about modelling and modelling tasks

Most participating teachers had known basically nothing about modelling tasks before the course, that is why we wanted to find out how their knowledge improved by the end of the course. We used the results of the pre- and the post test, the video recordings of the lessons and the tasks that were prepared during and after the course to collect information about their knowledge.

(2) Applied teaching methods

We wanted to find out how participants' own teaching had changed, to what extent did they build modelling tasks in their individual teaching compared to their earlier practice. We used the results of the pre- and the post test, the video recordings of the lessons and the parts of the interviews relating to the topic for this.

(3) Opinion on mathematics

The question here was how participants' opinion formed on mathematics had changed during the course and in their opinion how much of that change could be attributed to the course. We used the results of the pre- and the post test and the parts of the interviews relating to the topic to collect information about this.

(4) Pros and cons of the classroom application of modelling tasks

In the course participants elaborated the topics in groups, using partly cooperative methods, and discussed them together. During this they got a chance to understand the essence of the modelling process, the characteristics of the modelling tasks, to compare the structure of a modelling lesson to 


$$
\text { "tmcs-ambrus" — 2012/11/18 — 12:51 — page } 242 \text { — \#12 }
$$

a traditional one, they prepared a possible classification of the introduced tasks and they looked over a scheme of different aspects for the evaluation of students' work among others. Discussing the above mentioned pros and cons of classroom application was a highlighted topic. These were thought over and discussed in the beginning of the course for the first time, and then at the end of the course we reverted to them for a discussion. The comparison was based on all these.

Limits of the examination: due to the methods and the few elements of the sample we cannot draw a far-reaching conclusion. Some facts can be established though, as well as a few basic interdependences.

- During the sessions, participants were perceptively focusing on the educational task, immediately to the teaching practice. Theory was pushed into the background.

- The course filled quite a few needs of knowledge. It also helped to overcome several doubts and a great deal of helplessness.

- Preliminary individual teaching methods are a strong influence - as it had been expected - thus in the field of teaching methods, there are only minor changes.

- Partly due to the above mentioned, participants' quite good modelling knowledge in practice was usually less perceivable. (relatively few modelling classes, traditional methods)

- For the preparation of the course material it is fairly important to start from the teaching traditions of the reality-based tasks and then proceed towards new modelling knowledge.

- As for a positive experience, we can state that modelling tasks can successfully be built into traditional lessons, too.

Innovative, interested teachers took part in the course voluntarily - this is why it is difficult to estimate how others (the majority) would respond to these tasks and new ideas.

Finally, when summarizing our experiences a question occurred, namely that with good modelling skills, ability for preparing tasks, and self-reliance, why do teachers still refrain from the application of modelling tasks in the classroom and why are they still afraid of coming up with own ideas. The reason is to be searched mainly in the Hungarian teaching traditions. 


$$
\text { "tmcs-ambrus" — 2012/11/18 — 12:51 — page } 243 \text { — \#13 }
$$

\section{Conclusion}

One of the most important consequences of the course is that we succeeded in catching up with the recent major trends in mathematical modelling of the world or more specifically in Europe. The conference in Hamburg made the connection stronger and facilitated making new ones. In Hungary, there is a PhD student working on the topic, more and more university theses are written in modelling, and a new series of textbooks paying extra attention to it is being published. [14] The first four volumes of the series are currently being revised, and updated and their workbooks also contain modelling tasks.

The following major step will be the accreditation of the teacher training course in the topic. This will be an opportunity to extend the number of teachers being familiar with the opportunities of modelling in present day mathematics teaching thanks to the LEMA project. ELTE's Department of Mathematics has taken steps towards this direction, which can be seen in the attitude of the leaders of the Department. The first secondary school modelling competition conducted by László Lovász is to prove this. We have good hopes of this competition to become a tradition.

We make efforts to be able to follow some colleagues' school work in modelling and keep in touch with the participants via the webpage and in person, too.

\section{References}

[1] G. Ambrus, Modellezési feladatok a matematikaórán, RAABE Tanácsadó és Kiadó Kft., 2007 december 1-25.

[2] G. Ambrus, Valóságközeli matematikaoktatás tegnap és ma, (tanítási segédanyag 5-12. évfolyam számára), Tanári Kincsestár, RAABE Tanácsadó és Kiadó Kft. (2002. március), 2.1, 1-26.

[3] G. Ambrus and Ö. Vancsó, Modellezés az iskolai gyakorlatban, Matematika Tanítása 5 (2008), 3-11.

[4] W. Blum and D. Leiß, "Filling up"- The Problem of Independence-Preserving Teacher Interventions in Lessons with Demanding Modelling Tasks I., in: CERME-4 Proceedings of the Fourth Conference of the European Society for Research in Mathematics Education, Guixol, (M. Bosch, ed.), 2006.

[5] R. Fischer, Algemeinbildung, Studium Integrade (2000).

[6] G. Greefrath, Modellieren lernen, Aulis Verlag Deubner, Köln, 2007, 15.

[7] I. Hajnal, L. Számadó and Sz. Békéssy, Matematika 12, Nemzeti Tankönyvkiadó, 2004. 
[8] I. Lénárd, Non-euclidean adventures on the Lénárd Sphere, 2000.

[9] K. Maaß, Mathematisches Modellieren, Cornelsen Scriptor, Berlin, 2007, 12, 16.

[10] P. Maus and Ö. Vancsó, Egy EU-s projekt tapasztalatai, Matematika tanítása (2009), 5-12.

[11] G. Pólya, Mathematical Methods in Science, The Mathematical Association of America, Gondolat, 1977, 74-78, 103-110.

[12] G. Pólya, How To Solve It: a new aspect of mathematical method, Princeton, USA: Princeton University Press, 1945.

[13] A. Renkl, Träges Wissen: Wenn Erlerntes nicht genutzt wird, Psychologische Rundschau, Hogrefe-Verlag, Göttingen (1996), 47, 78-92.

[14] Ö. Vancsó, Matematika 9-12, Müszaki Könyvkiadó, 2006-2010.

[15] R. M. Zbiek and A. Conner, Beyond Motivation: Exploring mathematical modeling as a Context for Deeping Students' Understandings of Curricular Mathematics, Educational Studies in Mathematics 63, Springer (2006), 89-112.

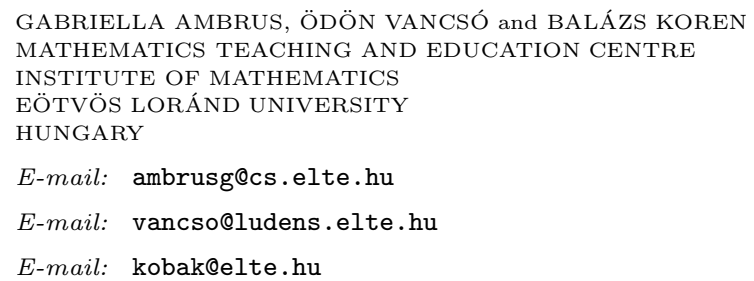

(Received June, 2011) 